\title{
The Comparing of Ultrasound-guided Techniques: Sciatic Block with Continuous Lumbar Plexus Block or Continuous Femoral Nerve Block for Anesthesia and Analgesia of Total knee Replacement
}

\author{
M. Dauri*, S. Faria, L. Celidonio, P. David, A. Bianco, E. Fabbi and M.B. Silvi
}

Department of Anaesthesiology, Emergency and Intensive Care Medicine, University Hospital of "Tor Vergata”, Rome, Italy

\begin{abstract}
Background and Aims: This double blind prospective randomized clinical trial evaluated the efficacy and safety of continuous ultrasound-guided lumbar plexus block compared to continuous ultrasound-guided femoral nerve block, in the intra-operative and postoperative periods after total knee replacement.

Methods: Forty ASA I-III patients were randomized to receive: continuous femoral block ( $\mathrm{n}=20,30 \mathrm{ml}$ of ropivacaine 5 $\mathrm{mg} / \mathrm{ml}$ ) or continuous lumbar plexus block $(\mathrm{n}=20,30 \mathrm{ml}$ of ropivacaine $5 \mathrm{mg} / \mathrm{ml}$ ) both in association with single injection sciatic nerve block. All patients received continuous infusion of $2 \mathrm{mg} / \mathrm{ml}$ of ropivacaine at $8 \mathrm{ml} / \mathrm{h}$ for 48 hours and intravenous morphine for patient-controlled analgesia. Primary outcomes were intra-operative sufentanil consumption and verbal analogue scale (VAS) score at rest at $24 \mathrm{~h}$ follow up.

Results: Intra-operative sufentanil consumption was higher in the femoral block (FEM) group compared to the lumbar plexus block (PSOAS) group (FEM: $10.00(10.00,17.50) \mu \mathrm{g}$; PSOAS: $2.50(0.00,10.00) \mu \mathrm{g} . \mathrm{p}=0.002)$.

Obturator motor blockade occurred more frequently in the PSOAS group (70\%) than in the FEM group (40\%) $(\mathrm{p}=0.1)$; however, we found no differences in sensory blockade $(\mathrm{p}=0.6)$.

VAS at rest was similar in the two groups at $24 \mathrm{~h}$ postoperatively (FEM: $29.50 \pm 14.74 \mathrm{~mm}$; PSOAS: $25.60 \pm 17.42 \mathrm{~mm}$. $\mathrm{p}=0.4$ ), and throughout the follow-up period. No differences were detected in pain scores during physiotherapy.

Conclusion: Continuous femoral and lumbar plexus blocks, both in association with sciatic nerve block, provided similar VAS scores at $24 \mathrm{~h}$, and throughout the follow-up period; intra-operative sufentanil consumption was, however, lower in the lumbar plexus block group.
\end{abstract}

Keywords: Continuous ultrasound-guided femoral nerve block, continuous ultrasound-guided lumbar plexus block, postoperative analgesia, total knee replacement.

\section{INTRODUCTION}

It is well known that suboptimal postoperative pain management after total knee replacement (TKR) is one of the main factors for physiotherapy and rehabilitation impairment and prolongation [1]. Several authors have demonstrated that continuous peripheral techniques represent a better side effect profile alternative than PCA or epidural analgesia after TKR, improving most of the common rehabilitation goals, through finer pain relief [1-3].

The role of femoral nerve block in this clinical setting, is well established [4]. However, obturator nerve blockade has a controversial role in TKR pain management. McNamee et al. [5] concluded in their trial that the addition of an obturator nerve block to femoral and sciatic blockade improves post-operative analgesia after TKR [5]. This could

\footnotetext{
*Address correspondence to this author at the Via Di S. Eufemia, 11, 00187 Rome, Italy; Tel: +39-06-6793660; Fax: +39-06-6793660;

E-mail: mario.dauri@fastwebnet.it
}

be explained considering that the three-in-one block does not involve the posterior branch of the obturator nerve [6], resulting in a less consistent blockade of this nerve than the lumbar plexus block (PSOAS) [5, 7]. However, Kaloul et al. [8] and Morin et al. [9] found no differences in postoperative pain relief comparing continuous lumbar plexus and femoral blockades, after TKR. None of these previous studies explored intra-operative time, nor did they use ultrasoundguided techniques.

Thus, the aim of this study was to compare the efficacy and safety of continuous ultrasound-guided lumbar plexus and femoral blocks for intra-operative anesthesia and for postoperative analgesia after TKR.

\section{METHODS}

\section{Patient Selection and Study Design}

This was a randomized double blind study design. After the approval of the study design by the "Tor Vergata University Ethics Committee", and having obtained written in- 
formed consent from each patient, we enrolled 40 American Society of Anesthesiologists (ASA) physical status class I-III patients who were scheduled for unilateral elective TKR; they were randomized by a computer-generated list to be allocated to one of the two groups: the FEM group received continuous ultrasound guided femoral nerve block and single shot ultrasound-guided sciatic nerve block $(n=20)$; the PSOAS group received continuous ultrasound-assisted lumbar plexus block and single shot ultrasound-guided sciatic nerve block $(n=20)$. Exclusion criteria included allergy to any local anesthetic; dementia with incomplete understanding; refusal of the procedure; ASA physical status class IV; use of psychotropic drugs (all drugs used in psychiatric disorders) and abuse of alcohol and drugs (the harmful or hazardous use of psychoactive substances, including alcohol and illicit drugs), severe hematological and coagulation disorders, severe rhythm disorders, neurological disorders (peripheral neuromuscular), local or systemic infection, history of chronic pain. Patients in the FEM group received continuous ultrasound-guided femoral nerve block and single shot ultrasound-guided sciatic nerve block, patients in the PSOAS group received continuous ultrasound-guided lumbar plexus block and single shot ultrasound-guided sciatic nerve block.

\section{Anesthetic Protocol}

Before surgery, patients underwent regional anesthesia after non-invasive monitoring and intravenous premedication with midazolam 1 to $3 \mathrm{mg}$.

FEM group: the patient was placed in the supine position: the groin was prepped and draped in sterile fashion; the same was done for the ultrasound probe. The physician applied the probe to the patient's groin and the femoral nerve sheath was visualized. A small skin wheal was made over the target site with lidocaine. The injection was made using a $50 \mathrm{~mm}$, 17-gauge insulated needle (Polymedic; Temena SARL, Bondy, France) attached to a syringe with $30 \mathrm{ml}$ of $5 \mathrm{mg} / \mathrm{ml}$ of ropivacaine, which was inserted in-plane with the probe. Once the needle came into view on the monitor, the tip was positioned posterior to the femoral nerve and the catheter was then inserted under the femoral nerve. After the needle was withdrawn, the catheter tip position was verified with the probe and ropivacaine solution was then injected. Finally, the catheter was tunneled and fixed with a sterile medication.

PSOAS group: the patient was placed in the lateral decubitus position with the side to be operated uppermost, and the area was prepared and draped in a sterile fashion. A $7 \mathrm{MHz}$ curved array $\mathrm{C} 11$ ultrasound probe, draped in a sterile manner, was applied to the patient's lumbar area in a cross-sectional fashion. The L3 spinous process and the transverse process of L3 were identified. After local anesthetic skin infiltration, a $120 \mathrm{~mm}, 17$-gauge insulated needle (Polymedic; Temena SARL, Bondy, France) connected to a peripheral nerve stimulator (Stimuplex; B. Braun, Melsungen, Germany) with initial current intensity of $1.0 \mathrm{~mA}(2 \mathrm{~Hz}$, 0.1 millisecond) was introduced in-plane with the probe. The lumbar plexus was finally identified by eliciting quadriceps contraction at current below $0.4 \mathrm{~mA}$. The catheter was then inserted in the needle and advanced $3 \mathrm{~cm}$ beyond the needle tip and a total of $30 \mathrm{~mL}$ of ropivacaine $5 \mathrm{mg} / \mathrm{ml}$ was injected in incremental doses. The needle was then withdrawn and the catheter was tunneled and fixed with a sterile medication.

Sciatic nerve block: the patient was left in the same lateral position. The ultrasound curved transducer was positioned on the line connecting the ischial tuberosity and greater trochanter, and the hyperechoic sciatic nerve was identified. After skin infiltration with $1 \%$ lidocaine, the block was performed with a short bevel $120 \mathrm{~mm}, 21$-gauge insulated nerve block needle inserted in-plane with the transducer with lateral to medial direction. A local anesthetic solution of $20 \mathrm{~mL}$ of $5 \mathrm{mg} / \mathrm{ml}$ of ropivacaine was then injected incrementally surrounding the nerve.

The same anesthesiologist, who had experience in both techniques, performed all procedures in both groups.

The observer was unaware of patient group allocation; moreover he was not present during the block execution, returning at the end of the procedure in order to collect the data required. Each patient had two catheters with filters fixed in the same way to the skin: the real catheter of the continuous block according to randomization and a phantom catheter from the area of the block not performed in order to keep both the patient and the observer blind. Both catheters were removed at $48 \mathrm{~h}$ of follow-up. Only the study coordinator and the anesthesiologist performing the chosen technique were informed, according to the randomization list.

Sensory and motor blockade of the FEM and PSOAS was assessed every five minutes until their appearance. Sensory and motor blockade of the obturator nerve was also recorded.

\section{Intra-operative Management and Follow-up}

In the operating room, ASA standard monitors were placed and vital signs recorded every 15 minutes.

During surgery, in event of pain expressed by the patient, sufentanil $(0.2-0.4 \mu \mathrm{g} / \mathrm{kg})$ was titrated until regression of pain. In the event of persistent patient discomfort, sedation could be administered with propofol in TCI (Target Controlled Infusion) mode (Orchestra ${ }^{\circledR}$ Base Primea, Fresesnius Kabi), Schneider pharmacokinetic protocol (initial target site-effect concentration of $1.5 \mu \mathrm{g} \mathrm{ml}$ ), maintaining spontaneous breathing. No local anesthetics were administered through the perineural catheter during the intra-operative period. At the end of the procedure, an elastomeric pump with $2 \mathrm{mg} / \mathrm{ml}$ of ropivacaine at $8 \mathrm{ml} / \mathrm{h}$ infusion rate was connected to the catheter of each patient of each group; each patient was also connected to a PCA device (I Pump, Baxter) set to deliver a $2 \mathrm{mg}$ morphine bolus, with $10 \mathrm{~min}$ lockout and a one hour limit of $8 \mathrm{mg}$ morphine. In the surgical ward, patients were able to request an additional analgesic (ketorolac $30 \mathrm{mg}$, maximum $90 \mathrm{mg} /$ day).

\section{Outcomes}

The primary outcomes of this study were VAS score at rest at $24 \mathrm{~h}$ and total intra-operative sufentanil consumption. Pain intensity was scored using a 0 to 100 verbal analogue scale (VAS). Pain scores at rest were noted before surgery, at the end of surgery, at $2 \mathrm{~h}, 6 \mathrm{~h}, 12 \mathrm{~h}, 24 \mathrm{~h}, 36 \mathrm{~h}$ and $48 \mathrm{~h}$ after surgery. Secondary outcomes were: pain score during physiotherapy (24h), $48 \mathrm{~h}$ postoperative morphine consump- 
tion (recorded at the end of surgery, $2 \mathrm{~h}, 6 \mathrm{~h}, 12 \mathrm{~h}, 24 \mathrm{~h}, 36 \mathrm{~h}$ and $48 \mathrm{~h}$ of follow-up), and the assessment of motor blockade of the femoral and obturator nerves. Motor blockade was evaluated testing the ability to straighten the operative leg against the hand of the examiner (FEM: end of surgery, $2 \mathrm{~h}$, $6 \mathrm{~h}, 24 \mathrm{~h}, 48 \mathrm{~h}$ ) or evaluating hip adduction, with knee flexed, against resistance (obturator nerve); movement was classified according to modified Bromage scale: no weakness $=0$; partial weakness $=1$; almost complete weakness $=2$; complete weakness $=3[10]$. Sensory blockade of the obturator nerve was assessed as decreased perception to ice over the internal medial area of the thigh. Intra-operative hemodynamic parameters, total intra-operative propofol consumption, patient and surgeon overall satisfaction were also recorded, assessed by a scale from 0 (unsatisfied) to 10 (very satisfied). All data were collected by a clinical research assistant, who was blinded to the technique used.

\section{Statistical Analysis}

To calculate the sample size an $\alpha$ error $=0.05$ (type I error probability for a 2 -sided independent $t$ test) and $\beta$ error $=0.2$ (power $80 \%$ ) was accepted. Our first hypothesis $\left(\mathrm{H}_{1}\right)$ was to find at least a difference of $60 \%$ in the use of intraoperative sufentanil required. Our second hypothesis $\left(\mathrm{H}_{2}\right)$ was to find at least a VAS difference between groups of 20 $\mathrm{mm}$, during the post-surgery follow-up.

Minimal sample sizes of 36 patients (18 in each group) and 34 patients (17 in each group) for the two clinical settings, respectively, met these criteria. Thus 20 patients for each group were recruited to allow for incomplete data collection. We based analyses on the intention to treat principle; we thus included all randomised patients who had potentially ultrasound guided regional anestesia and analgesia for TKR.The t-test was used to analyze normally distributed numeric variables. For non-parametric variables, the MannWhitney U test was used. Categorical differences were tested using the Yates's chi-square test or the Fisher exact method depending on the size of the observed frequencies. A p-value $<0.05$ was considered statistically significant. Statistical analyses were performed using the free software $G^{*}$ Power version 3.1.4 (Faul, Erdfelder, Lang, \& Buchner, 2009) and the commercial software MATLAB version R2011a (MathWorks, Natick, Massachusetts, USA).

\section{RESULTS}

A total of 40 patients were assessed for eligibility and all were analyzed following an intention-to-treat method $(\mathrm{FEM}=20, \mathrm{PSOAS}=20)$. There were 2 patients whose catheters were accidentally removed in the early period of followup, both in the PSOAS group. There were no significant differences between the two groups according to sex, age, ASA score, BMI and preoperative values (Table $\mathbf{1}$ ).

The total amount of intra-operative sufentanil consumption was lower in the PSOAS group ( $\mathrm{p}=0.002$ ) (Table 3).

VAS score at rest was similar in the two groups, both at 24h postoperatively (FEM: $29.50 \pm 14.74 \mathrm{~mm}$; PSOAS: $25.60 \pm 17.42 \mathrm{~mm} ; \mathrm{p}=0.4)$ and throughout the postoperative follow-up period (Fig. 1a; Fig. 1b).

There were no differences in pain scores during physiotherapy (24h) (FEM $39.4 \pm 27.5 \mathrm{~mm}$; PSOAS $40.6 \pm 23.7$ $\mathrm{mm} ; \mathrm{p}=0.7)$.

Total morphine self-administration was similar in the two groups throughout the postoperative follow up period (FEM:

Table 1. Demographic Data

\begin{tabular}{|l|c|c|c|}
\hline & FEM (N=20) & PSOAS (N=20) & p-value \\
\hline \hline Age (years) & $75.00(68.50,78.00)$ & $74.00(65.00,78.00)$ & 0.6 \\
\hline Sex (M/F) & $6 / 14$ & $7 / 13$ & 0.7 \\
\hline Height (cm) & $165.00(160.00,172.50)$ & $164.00(158.50,168.00)$ & 0.3 \\
\hline Weight (Kg) & $81.00(71.50,87.50)$ & $73.00(68.00,82.50)$ & 0.08 \\
\hline BMI (Kg/m) & $30.00(27.00,31.50)$ & $28.00(25.00,31.00)$ & 0.3 \\
\hline ASA I & 1 & 2 & 13 \\
\hline II & 17 & 5 & 0.3 \\
III & $139.10 \pm 23.64$ & $137.55 \pm 17.42$ & 0.1 \\
\hline SBP- pre (mmHg) & $80.50 \pm 77.50,90.00$ & $75.00 \pm 68.50,82.00$ & 0.4 \\
\hline DBP- pre (mmHg) & $99.50 \pm 14.07$ & $96.30 \pm 11.85$ & 0.5 \\
\hline MBP- pre (mmHg) & $68.30 \pm 8.89$ & $70.05 \pm 6.17$ & 0.2 \\
\hline BPM- pre (bpm) & $13.35(12.3,14.4)$ & $12.60(12.3,13.6)$ & \\
\hline Hb- pre (mg/dl) & & & \\
\hline
\end{tabular}

FEM = continuous femoral nerve block; PSOAS = continuous posterior lumbar plexus block. Age, weight, height, BMI, ASA and Hemoglobin (Hb) are expressed as median (IQR) and range. SBP- pre, DBP-pre and MBP-pre are expressed as mean \pm standard deviation. SBP: systolic blood pressure. DBP: diastolic blood pressure. MBP: mean blood pressure. -pre: preoperative values. 
Table 2. Assessement of Motor Block of Femoral Nerve Throughout 48h of Follow Up

\begin{tabular}{|c|c|c|c|}
\hline Motor block & FEM (n ${ }^{\circ}$ 20) & PSOAS (n ${ }^{\circ}$ 20) & p-value \\
\hline \hline End of surgery & $3.00(3.00,3.00)$ & $3.00(3.00,3.00)$ & 0,7 \\
\hline $2 \mathrm{~h}$ & $3.00(3.00,3.00)$ & $3.00(3.00,3.00)$ & 0,2 \\
\hline $6 \mathrm{~h}$ & $3.00(2.00,3.00)$ & $3.00(2.00,3.00)$ & 0,6 \\
\hline $12 \mathrm{~h}$ & $2.00(2.00,2.00)$ & $2.00(2.00,2.50)$ & 0,9 \\
\hline $24 \mathrm{~h}$ & $1.00(1.00,2.00)$ & $2.00(1.00,2.00)$ & 0,1 \\
\hline $36 \mathrm{~h}$ & $1.00(1.00,1.50)$ & $1.50(1.00,2.00)$ & 0,3 \\
\hline $48 \mathrm{~h}$ & $1.00(0.50,1.50)$ & $1.00(1.00,2.00)$ & 0,3 \\
\hline
\end{tabular}

Movement was classified as follows: no weakness $=0$; partial weakness $=1$; almost complete weakness $=2$; complete weakness $=3$. Data are expressed as median (IQR) and range.

5.50 (1.50, 10.00); PSOAS: $6.00(3.00,7.00) ; \mathrm{p}=0.7)$ (Fig. 2a, Fig. 2b).

After anesthesia, the rate of obturator nerve motor blockade was higher in the PSOAS group (70\%) than in the FEM group (40\%); however, sensory blockade of the same nerve was similar between groups $(\mathrm{p}=0.6)$. Concerning motor blockade of the femoral nerve, this was similar between groups throughout the follow-up (Table 2).

Intra-operatively, there were no differences between groups regarding the amount of propofol infused, or surgery (and tourniquet duration (Table 3). Hemodynamic parameters were similar between groups during surgery, including the times of the most painful stimuli (incision, femoral bone resection, and tibial bone resection) (Table 3 ).

There were no differences regarding postoperative hemodynamic data during the follow-up or in rescue ketorolac consumption ( $\mathrm{p}=0.9)$ (data not shown).

Postoperative blood loss from drainages was similar in the two groups (FEM: $779.50 \pm 212.99$; PSOAS: $821.00 \pm$ 295.10; $\mathrm{p}=0.6)$ as was hematic hemoglobin concentration before $(\mathrm{p}=0.1)$, and $24 \mathrm{~h}(\mathrm{p}=0.06)$ and $48 \mathrm{~h}(\mathrm{p}=0.6)$ after sur-

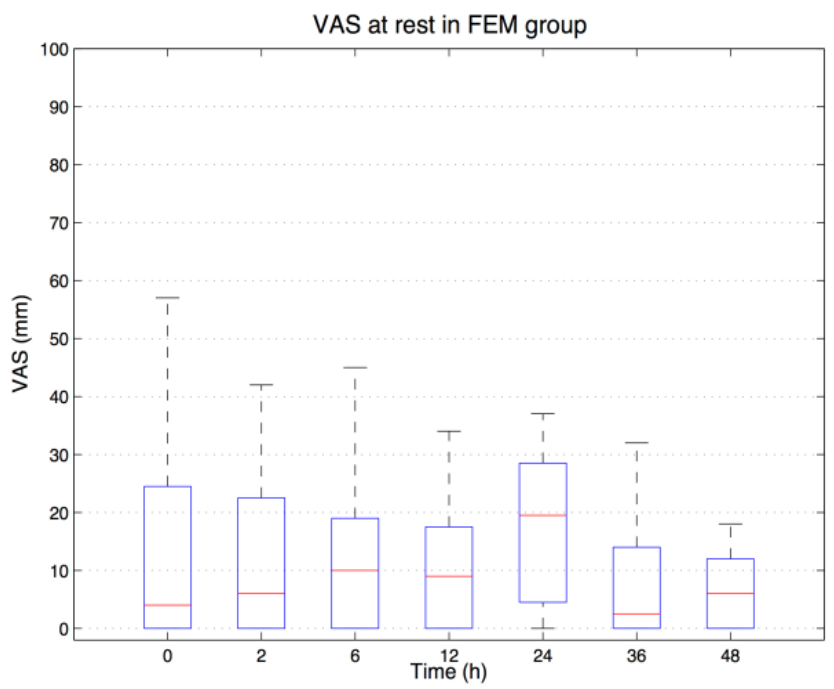

Fig. (1a). VAS at rest in FEM group throughout the follow up period. Data are shown as median (IQR) and range. gery. A total of 23 patients were transfused after surgery, with no differences between groups. Regarding complications, there were no differences regarding postoperative nausea (FEM: $30 \%$; PSOAS: $25 \%$; $\mathrm{p}=1.0$ ) and vomiting (FEM: $10 \%$; PSOAS: $20 \%$; $=0.6$ ) between groups. Only two patients in the FEM group reported post-operative pruritus $(\mathrm{p}=0.5)$. There were no adverse effects linked to perineural injection of ropivacaine. No technique-related complications were reported.

There were no significant differences between the groups in terms of surgeon satisfaction ( $\mathrm{P}=0.08)$; patient satisfaction was greater for the PSOAS group than for the FEM group $(\mathrm{P}=0.01)$.

\section{DISCUSSION}

The results of this study demonstrate that both FEM and PSOAS blocks provided satisfactory surgical anesthesia and similar VAS during the first 48 hour postoperatively. However, overall intra-operative sufentanil consumption was reduced in the PSOAS group (Table 3), probably thanks to the higher rate of obturator nerve territory involvement by lumbar plexus block compared to femoral nerve block. We evaluated obturator nerve blockade assessing the hip adduc-

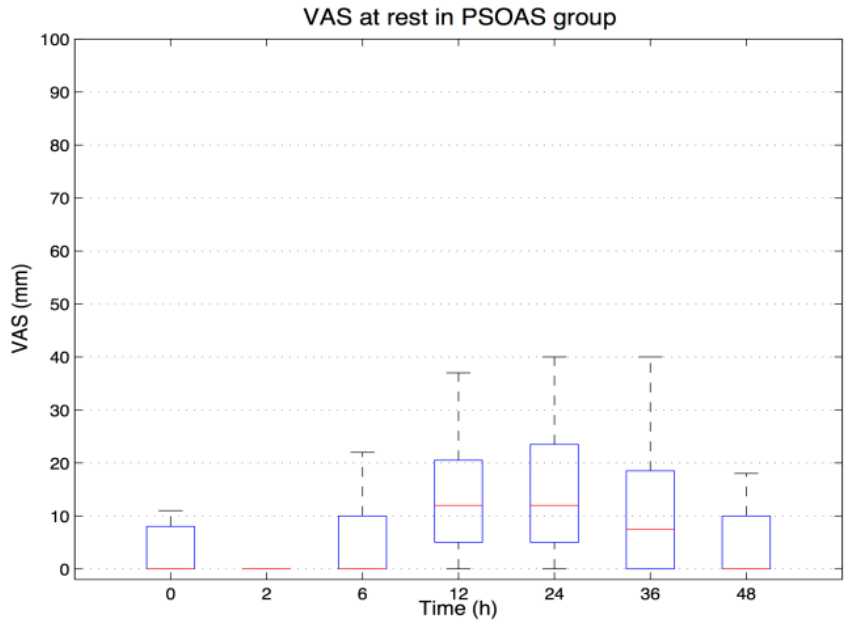

Fig. (1b). VAS at rest in PSOAS group throughout the follow up period. Data are shown as median (IQR) and range. 


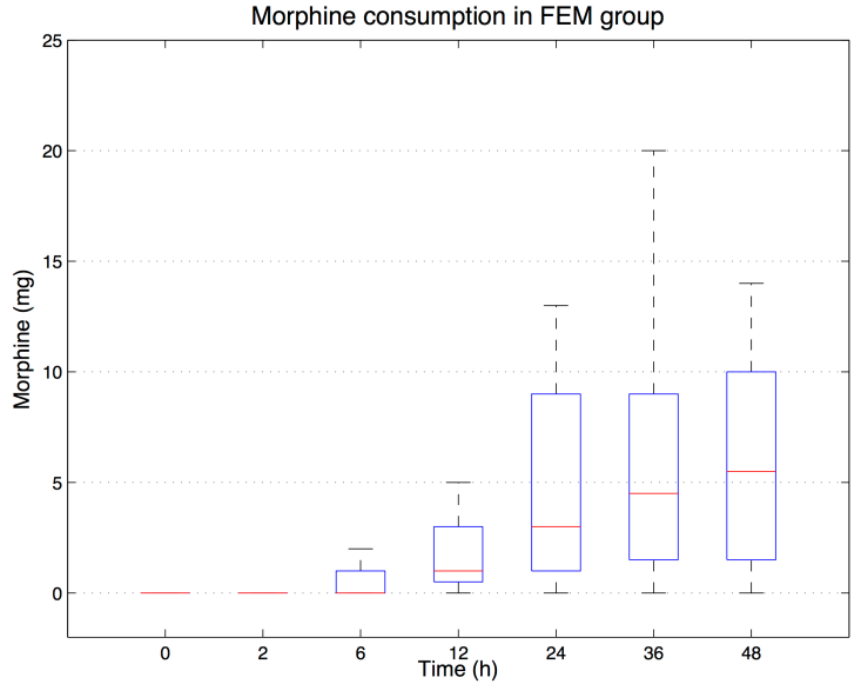

Fig. (2a). morphine consumption in FEM group throughout the follow up period. Data are expressed as median (IQR) and range.

tor strength, considering the finding of Bouaziz et al. who demonstrated that the cutaneous distribution of the obturator nerve is not only highly variable but may even be incomplete or totally absent (57\% of the patients) [11]. To our knowl-

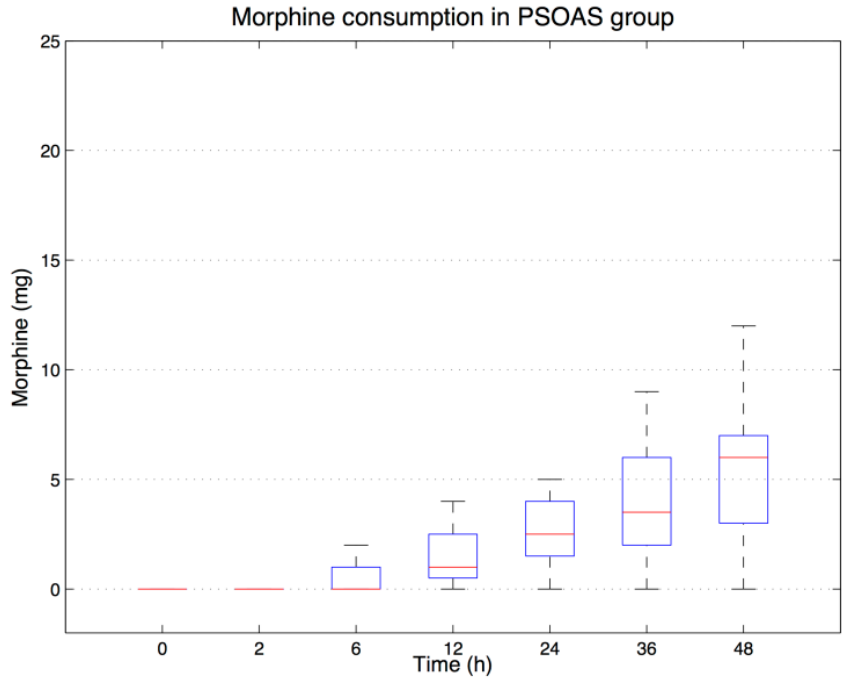

Fig. (2b). morphine consumption in PSOAS group throughout the follow up period. Data are expressed as median (IQR) and range.

edge, there are currently no studies that explore whether adding obturator nerve block to femoral nerve blocks results in improved intra-operative TKR management.

Table 3. Intraoperative Data

\begin{tabular}{|c|c|c|c|}
\hline & $\operatorname{FEM}(\mathbf{n}=20)$ & PSOAS $(n=20)$ & p-value \\
\hline \multicolumn{4}{|l|}{ Skin incision } \\
\hline $\mathrm{SBP}(\mathrm{mmHg})$ & $145.45 \pm 37.92$ & $139.30 \pm 32.02$ & 0.6 \\
\hline DBP (mmHg) & $79.00(69.50,80.50)$ & $70.00(64.00,82.00)$ & 0.3 \\
\hline MBP (mmHg) & $100.00(87.50,106.00)$ & $88.50(82.50,109.00)$ & 0.7 \\
\hline HR (bpm) & $66.00(60.00,77.00)$ & $61.50(57.50,66.00)$ & 0.1 \\
\hline \multicolumn{4}{|l|}{ Femoral bone resection } \\
\hline $\mathrm{SBP}(\mathrm{mmHg})$ & $132.95 \pm 29.49$ & $132.95 \pm 29.49$ & 0.6 \\
\hline DBP (mmHg) & $70.90 \pm 15.01$ & $69.50 \pm 13.48$ & 0.8 \\
\hline MBP (mmHg) & $91.55 \pm 18.41$ & $89.30 \pm 16.79$ & 0.7 \\
\hline HR (bpm) & $63.00(58.50,69.00)$ & $59.50(55.50,66.00)$ & 0.3 \\
\hline \multicolumn{4}{|l|}{ Tibial bone resection } \\
\hline $\mathrm{SBP}(\mathrm{mmHg})$ & $127.95 \pm 28.85$ & $129.00 \pm 25.30$ & 0.9 \\
\hline $\mathrm{DBP}(\mathrm{mmHg})$ & $71.45 \pm 14.25$ & $67.15 \pm 12.26$ & 0.3 \\
\hline MBP (mmHg) & $90.35 \pm 17.58$ & $87.75 \pm 15.38$ & 0.6 \\
\hline $\mathrm{HR}(\mathrm{bpm})$ & $59.00(55.00,69.50)$ & $59.00(56.00,66.50)$ & 0.9 \\
\hline Propofol (mg) & $500.00(295.00,728.00)$ & $358.50(42.00,578.00)$ & 0.1 \\
\hline Sufentanil $(\mu \mathrm{g})$ & $10.00(10.00,17.50)$ & $2.50(0.00,10.00)$ & 0.002 \\
\hline Tourniquet (min) & $77.85 \pm 22.13$ & $83.70 \pm 14.60$ & 0.3 \\
\hline Surgery duration (min) & $104.25 \pm 19.89$ & $104.50 \pm 30.08$ & 0.9 \\
\hline
\end{tabular}

Data are espressed as Mean \pm SD or as median (IQR) and range. SBP: systolic blood pressure. DBP: diastolic blood pressure. MBP: mean blood pressure. HR: heart rate. 
We know, however, from anatomy studies that the posterior branch of the obturator nerve terminates by passing through the adductor hiatus to enter the popliteal fossa, supplying the posterior aspect of the knee joint and the popliteal artery. Considering all these data, we could argue that obturator nerve block could be important for intra-operative TKR management, but we cannot affirm this only on the basis of our trial results.

Considering the postoperative period, the question whether or not obturator nerve block improves postoperative analgesia still remains unclear. McNamee et al. [5] affirm that the addition of an obturator nerve block improved postoperative analgesia following total knee replacement; however, while our results show a higher rate of obturator nerve involvement in the PSOAS group, there were no differences between the two techniques in terms of VAS pain scores and total morphine consumption after TKR. In agreement with our trial, Kaloul et al. [8] suggest that obturator nerve involvement does not improve postoperative pain scores after TKR; Morin et al. [9] come to the same conclusion. Preliminary results by Lund et al. go in the opposite direction: continuous adductor-canal-blockade may be a valuable adjunct for post-operative analgesia after major knee surgery [12]. With this scenario we can affirm that, both for the intraoperative and postoperative period after TKR, the role of obturator nerve block remains unclear and further trials are therefore necessary to clarify this aspect. Considering our trial results, we could argue that obturator nerve block could be important for intra-operative management but is not necessary for the postoperative period.

We did not detect any differences in post operative complications between the groups. Only one patient in the PSOAS group reported post-operative pruritus. There were no adverse effects linked to perineural injection of ropivacaine; however, the power chosen for the study may have led to a false negative result. We chose a single anesthesiologist with considerable experience in peripheral nerve block, to manage all the patients, thus reducing methodological bias.

There are several reports about serious adverse complications linked to the continuous lumbar plexus technique (total spinal anesthesia, epidural spread of local anesthetic, acute local anesthetic toxicity, and renal subcapsular, psoas and retroperitoneal hematomas) [13-18], despite weak benefits observed over the femoral technique.

Ultrasound guidance, however, may increase the safety and efficacy of both techniques [19,20]. Above all for lumbar plexus block, this could translate into higher success rates and reduced needle-related complications [21].

Continuous femoral and lumbar plexus blocks, both in association with sciatic nerve block, provided similar VAS scores at all times of the follow-up. Intra-operative sufentanil consumption was reduced in the lumbar plexus block group; however, the clinical significance of this finding is unclear.

Analyzing both technique-related complications, continuous ultrasound-guided femoral nerve block seems to be the best choice considering the risk/benefit balance. Whether to add obturator nerve block for the intra-operative period requires further evaluation.

\section{CONFLICTS OF INTEREST}

The authors confirm that this article content has no conflicts of interest.

\section{ACKNOWLEDGEMENTS}

This was a not for profit trial.

\section{REFERENCES}

[1] Singelyn FJ, Deyaert M, Joris D, Pendeville E, Gouverneur JM Effects of intravenous patient-controlled analgesia with morphine, continuous epidural analgesia, and continuous three-in-one block on postoperative pain and knee rehabilitation after unilateral total knee arthroplasty. Anesth Analg 1998; 87: 88-92.

[2] Capdevila X, Barthelet Y, Biboulet P, et al. Effects of perioperative analgesic technique on the surgical outcome and duration of rehabilitation after major knee surgery. Anesthesiology 1999; 91: 8-15.

[3] Chelly JE, Greger J, Gebhard R, et al. Continuous femoral blocks improve recovery and outcome of patients undergoing total knee arthroplasty. J Arthroplasty 2001; 16: 436-45.

[4] Fischer HB, Simanski CJ, Sharp C, et al. A procedure-specific systematic review and consensus recommendations for postoperative analgesia following total knee arthroplasty.Anaesthesia 2008; 63: 1105-23.

[5] McNamee DA, Parks L, Milligan KR. Post-operative analgesia following total knee replacement: an evaluation of the addition of an obturator nerve block to combined femoral and sciatic nerve block. Acta Anaesthesiol Scand 2002; 46: 95-9.

[6] Marhofer P, Nasel C, Sitzwohl C, Kapral S. Magnetic resonance imaging of the distribution of local anesthetic during the three-inone block. Anesth Analg 2000; 90: 119-24.

[7] Parkinson SK, Mueller JB, Little WL, Bailey SL. Extent of blockade with various approaches to the lumbar plexus. Anesth Analg 1989; 68: 243-8.

[8] Kaloul I, Guay J, Côté C, Fallaha M. The posterior lumbar plexus (psoas compartment) block and the three-in-one femoral nerve block provide similar postoperative analgesia after total knee replacement. Can J Anaesth 2004; 51: 45-51.

[9] Morin AM, Kratz CD, Eberhart LH, et al. Postoperative analgesia and functional recovery after total-knee replacement: comparison of a continuous posterior lumbar plexus (psoas compartment) block, a continuous femoral nerve block, and the combination of a continuous femoral and sciatic nerve block. Reg Anesth Pain Med 2005; 30: 434-45.

[10] Bromage PR. Epidural Analgesia. Philadelphia, PA: WB Saunders 1978.

[11] Bouaziz H, Vial F, Jochum D et al. An evaluation of the cutaneous distribution after obturator nerve block. Anesth Analg 2002; 94: 445-9.

[12] Lund J, Jenstrup MT, Jaeger P, Sørensen AM, Dahl JB. Continuous adductor-canal-blockade for adjuvant post-operative analgesia after major knee surgery: preliminary results. Acta Anaesthesiol Scand 2011; 55: 14-9.

[13] Gentili M, Aveline C, Bonnet F. Total spinal anesthesia after posterior lumbar plexus block (French). Ann Fr Anesth Réanim 1998; 17: 740-2.

[14] Pham-Dang C, Beaumont S, Floch H, et al. Acute toxic accident following lumbar plexus block with bupivacaine (French). Ann Fr Anesth Réanim 2000; 19: 356-9.

[15] Klein SM, D'Ercole F, Greengrass RA, Warner DS. Enoxaparin associated with psoas hematoma and lumbar plexopathy after lumbar plexus block. Anesthesiology 1997; 87: 1576-9.

[16] Aida S, Takahashi H, Shimoji K. Renal subcapsular hematoma after lumbar plexus block. Anesthesiology 1996; 84: 452-5.

[17] Weller RS, Gerancher JC, Crews JC, Wade KL. Extensive retroperitoneal hematoma without neurologic deficit in two patients who underwent lumbar plexus block and were later anticoagulated. Anesthesiology 2003; 98: 581-5.

[18] Dauri M, Faria S, Celidonio L, et al. Retroperitoneal haematoma in a patient with continuous psoas compartment block and enoxaparin administration for total knee replacement. $\mathrm{Br} \mathrm{J}$ Anaesth 2009; 103 : 309-10. 
[19] Hadzic A, Sala-Blanch X, Xu D. Ultrasound guidance may reduce but not eliminate complications of peripheral nerve blocks. Anesthesiology 2008; 108: 557-8.

[20] Kirchmair L, Entner T, Kapral S, Mitterschiffthaler G. Ultrasound guidance for the psoas compartment block: an imaging study. Anesth Analg 2002; 94: 706-10.
[21] Karmakar MK, Ho AM, Li X, et al. Ultrasound-guided lumbar plexus block through the acoustic window of the lumbar ultrasound trident. Br J Anaesth 2008; 100: 533-7.

Received: March 23, 2013

Revised: April 10, 2013

Accepted: April 12, 2013

(C) Dauri et al.; Licensee Bentham Open.

This is an open access article licensed under the terms of the Creative Commons Attribution Non-Commercial License (http://creativecommons.org/licenses/by-nc/3.0/) which permits unrestricted, non-commercial use, distribution and reproduction in any medium, provided the work is properly cited. 